\title{
Research on Marketing Strategy of Hefei Wanda Plaza
}

\author{
Liu Yan \\ International Business School, Shaanxi Normal University \\ Xi'an, Shaanxi 710119 \\ 604493995@qq.com
}

\begin{abstract}
With the improvement of the living standard, the demand for the service industry is increasing. Wanda created original business model is widely praised in Hefei, and it is well received. The research on the marketing strategy of Wanda Plaza provides reference for the integrated commercial model of other cities. This paper uses the STP theory and the 4P strategy research method to study the transport of Wanda Plaza in Hefei. This paper draws the following conclusions: 1. Hefei Wanda Plaza has a superior geographical position, such as a modern mainstream commercial pedestrian street, and a main entertainment and leisure place for the high education and high income group; 2. The marketing mode of Hefei Wanda Plaza is staircase pricing. According to the needs of different groups for different shops, different prices have been made to satisfy the sense of belonging of customers; 3. Wanda Plaza is mainly dependent on brand advantage. Both its commercial square and bar street depend on brand integration and expand with the rapid economic development in the future.
\end{abstract}

Keywords-Hefei City; Wanda Plaza; Real Estate; Strategy

\section{INTRODUCTION}

In December 2010, the first Wanda Plaza located on Wuhu Road and Ma on Shan Road in Hefei, opened with a grand opening. To the north in the Westin Hotel and Riverside Bar Street. Wuhu Road south of the bus and subway traffic is convenient. According to relevant reports, Wanda is the largest commercial center in Hefei. At the same time, Hefei City invested the largest scale of urban commerce. The third generation city complex Wanda Square for the project planning concept. Nowadays, Hefei has three Wanda Square, namely Wuhu Road Wanda Square, Swan Lake Administrative District Wanda Square and Yaohai Wanda Square. Wanda Square is the center of the provincial capital for Hefei. I believe that Wanda will become Hefei a shiny new business card.

\section{SWOT ANALYSIS OF WANDA PLAZA IN HEFEI}

\section{A. Advantages}

Wanda Square has become an indispensable core position in developed cities, forming a scale effect. Its operator is the largest real estate operator in China. Wuhu Road Wanda Square is located at Ma on Shan Road, superior geography and convenient transportation. There have more shopping malls around the center that can satisfy the needs of consumers .In addition, Wanda has taken advantage of its brand and resources to expand. At present, Hefei has established three Wanda Square, occupying the main commercial and real estate resources. Our investment Wanda hospital line and thousands of department stores development is pretty good, so competitive in the industry.

\section{B. Disadvantages}

Up to now, in the property occupied by Wanda Square itself, the partners with low rent account for more than $70 \%$ of the whole square. Because the level of rent is relatively low, the level of commercial tenants is also limited, especially the small and medium-sized shops. The economic benefits need to be improved, and the profits of commercial tenants are also relatively low. Moreover, the prices of goods in shopping malls are too high. Consumers buy goods under the market, thus reducing purchases of commodities. The profits of enterprises are reduced, and the rents of stores are also high, which will lead to low rates of return on rents. It usually between four and six percent.

\section{Opportunities}

Wanda Square positioning to increase leisure and entertainment experience business. Increasing the consumption time to enhance the consumer experience effect, hoping to change the core store rent level low state, to solve the obstacles to the development of Wanda. Based on the domestic market has not yet matched the competition, coupled with the consumer power of residents taste is constantly changing. 


\section{Threats}

Since 2010, with the rapid expansion and acquisition of land, the enterprise capital chain is shrinking. At present, the shortage of professional management personnel and market management personnel resources hinders the development of Wanda and lags behind the progress of Wanda subsequent management. Blindly pay attention to sales cash flow and market fluctuations, easy to cause some potential adverse effects.

\section{WANDA SQUARE PRODUCT STRATEGY}

The commercial complex of the city, Hefei Wanda Plaza mainly includes the following aspects:

\section{A. The Westin hotel}

As the first six star hotel in Hefei, the overall quality of the hotel in Hefei has been greatly improved. The Wenstin hotel is located in Hefei and is the fourth central city following the North top of the city. As the first six star hotel in Hefei, the Wenstin hotel is living in a large scale to improve the overall temperament of Hefei city. It can become an elephant. The representative of the city status, because we know the grade of the hotel is the city is the city undefined economic strength. The Westin Hotel is seen as the most important guest, like Shanghaiundefineds Kim Yue.

\section{B. The Super A office building}

Super Grade A landmark office building is the first modern twin building in Hefei, and the concept of environmental protection is introduced to reduce pollution and improve office quality. On the other hand, the super A office building is also an important symbol of the city image and strength, which condenses many enterprises that can promote the city economy and promote the city scale. It can be said that having this place is like having a lever to leverage Hefeiundefineds office city.

\section{The Wanda Mansion}

Wanda mansion embodies the process and development of the living environment of urban residents, and is the representative of the strength and height of urban human settlements. Wanda Group, with 20 years of experience in the development of luxury homes and exchanges and cooperation with many international first-line brands, estimates that the decoration standard per square metre will reach a high price of more than 3000 yuan, thus creating the first luxury house in Hefei. Perfect interpretation of Wandaundefineds definition of luxury house. Here, we can not only enjoy the convenience of prosperous life, but also improve personal taste and quality of life.

\section{The Wanda Shopping Center}

Wanda Shopping Center showcases the cityundefineds desires and tastes and strives to turn the mall into one of Hefeiundefineds top leisure and entertainment centers. The worldundefineds top brands, and hand in hand with international first-line brands, to meet the people of Hefei popular brand and trend pursuit. Can promote the taste of the city at the same time perfect deduction of the cityundefineds charm. In Wanda Square, experience is the worldundefineds top fashion trends, feeling the world tide development trend.

\section{E. The pedestrian mall}

Sometimes the shopping habits and brand preferences of local consumers can be fully judged from the scale and pattern of urban pedestrian streets. Wanda commercial pedestrian street will give a new definition of the city, leisure, entertainment, dining and shopping streets, and gradually become representative of the taste of life attitude. Even old people and young children can walk here. Take a walk. Can get every minute of the rest of the feeling.

\section{WANDA SQUARE PRICING STRATEGY}

\section{A. The main methods of pricing}

\section{1) Goal-oriented}

Wanda Square cannot be priced at the cost of the development square, which will not only lower grade, but also make consumers feel uncompetitive. Shopping malls, office buildings and upscale residential areas are selected as the target market for the upper and middle income earners of the city. According to the estimated annual income and expenditure of consumers in the survey, the purchasing intention of the customers is calculated. In order to be able to better sell goods. From the central positioning can be seen Wanda Square target market income groups.

\section{2) Demand differential pricing}

The price of shop is different, according to different customers and different forms. The main pricing ideas are as follows: first of all, the price scale should be set, the price of the core sections such as the exit and entrance on the first floor of Wanda shopping mall, the intersection of Cross Street in Jinjie should be compared one by one, and the price should be allocated reasonably. The main method of pricing is product differential pricing method. The shop price between the first ring, the second ring and the third ring should be set reasonably to meet the different levels of consumer demand;

\section{B. The basic pricing strategies}

\section{1) Psychological pricing strategy}

It mainly uses the reputation of Wanda Group to set prices; first, it communicates with the local government to understand the needs of customers, and then it tries to raise the prices of shops according to the building standard. When pricing, the comprehensive facilities such as office buildings have to be considered one by one, such as daylighting. According to the price accepted by customers, give a certain function discount, not only make Wanda shops sell out as soon as possible, but also improve the reputation of Wanda. 


\section{2) Cash discount pricing strategy:}

Some special floors, such as major customer offices or government offices, should not be priced uniformly and individualized. According to the situation of Hefei staff market research, the price of office buildings is acceptable to ordinary people, and a certain discount will be given to customers who pay according to the agreed date. Or for the short loan repayment period customers can also give some concessions, Wanda Square shops to take the time of the opening of the morning and evening and the intention of consumers to collect information to purchase pricing.

\section{3) Skimming pricing strategy:}

At the opening of Wanda Square, market prices soared. In addition to some poor locations and floors, the prices of houses and shops in other locations were higher than those in Hefei. Wanda Square is the center of the city because of Wanda Group prestige, the limited number of shops and the fact that the owners of the shops know that Wanda Square is the center of the city. With this positioning, Wanda to their own shops on the price of higher prices. For example, at the opening of a shop along Wuhu Road, the price reaches 9473 yuan per square meter; in the city center of Hefei, where prices are now soaring, the price of the Wanda Square reaches 22132 yuan per square metre. Higher than the average consumer range of heart, a short period of time will be very difficult to draw.

\section{4) Differential pricing method:}

As far as Wanda shops in Hefei are concerned, the prices of shops in each region are different. In general, Wanda formulates the prices of shops on the basis of road, population flow and commercial planning; for example, the price of shops on Chaohu Road is 15595 yuan per square metre. Now the price of Wuhu Road is more than 37000 yuan per square meter, more than half the price of Chaohu Road, from which we can see that the more downtown the more expensive the price.

\section{Distribution STRATEGY OF WANDA SQUARE}

\section{A. Exclusive distribution of shopping malls}

Wanda Plaza adopts self-owned mode, which is operated by shop owners independently, in which Wanda shopping mall operates as turnover deduction, which accounts for $25 \%$ of turnover, and the proportion of deduction points varies according to brand and location. Indoor Pedestrian Street for Wanda rental operation, a total of three levels. Prices vary from floor to floor. The outdoor pedestrian street for a total of two floors, a start is sold directly to the outside, the current understanding of the situation is the owner of their own investment. The first floor rents about twice as much as the second floor. The core commercial part only rents and does not sell. For example, there are about 20 or so shops on each floor in Wanda Square interior pedestrian street. Each of the shops here is a shop that rents Wanda shopping malls, pays rent every year, and will never buy a shop in person.

\section{B. On-line and off-line distribution in upscale residential areas}

Wanda Squareundefineds high-grade residential housing sales use online and offline joint sales situation, Hefei real estate is growing in recent two years, plus a lot of customers busy with no time, fewer and fewer customers to see the house. Wanda Group makes use of the Internet to make the building specifications and housing related information publicly available on the Internet, so that customers will first have time to browse the Internet for themselves, and wait until there is an interesting property to appear, and go directly to Wanda Real Estate to inquire about the relevant prices. Thus facilitating the completion of the purchase of housing transactions.

\section{Wanda Plaza Business Promotion StRategy}

\section{A. Promotion of principles}

\section{1) Mighty}

Strong means to establish a strong image of the project, representing a strong attitude to promote the Hefei Wanda project. [11] regardless of the construction of Wanda Square project brand, or Wanda unique brand in Hefei. Should show economic strength and economic status in a strong attitude. Let Hefei people trust Wanda and set up a good image of Wanda Square.

\section{2) Occupying Position}

Wanda Square is the center of Hefei City, hoping to create an integrated service industry to meet a variety of consumer needs, so that people can think of Wanda Square as soon as they think about shopping.

\section{B. Business promotion activities}

\section{1) Entering the market based on Wanda Group Brand}

Two main business promotion activities: Wanda China experience activities and Wanda brand promotion activities. These two kinds of business promotion activities are mainly to expand the influence of Wanda brand in Hefei city. As a result, the market and customers are pay more attention to it, thus increasing Wanda presence in Hefei and increasing market confidence.

(1)Wanda experience China Travel: The idea of the event is that Wanda Group, as the organizer, first invited local news media and key project customers to visit the launching ceremony of Wanda Square, so that everyone could see Wanda Square enter Hefei and experience the charm of the city complex together. At the same time comprehensive tracking shooting and production of photo albums. The main purpose of using the news media to track and report on Wanda is to get the residents of Hefei to recognize Wanda Square.

(2)Wanda brand DAY: In order to improve brand influence, Wanda Square held brand promotion activities. The main ideas are: first of all, we should choose Wanda Square in the urban center of the project display. In Hefei, for example, you can choose to hold it in a ring, you can buy it in the city square, or you can buy it in the country. Brand stores should be filled with the whole city square and create a sensation. Better can let the city citizen see Wanda and other square different place, display Wanda strength. 


\section{CONCLUSION}

Wanda Square is located in the center of the city, dedicated to building high standards, internationalization, to meet the diverse consumer needs, in line with the mainstream choice of contemporary consumers. Using STP theory and 4P strategy, this paper studies the marketing model of Hefei Wanda Square and draws the following conclusion: 1. Hefei Wanda Square has a superior geographical location, mainly located in the city center or business district of various regions. It is the modern mainstream commercial pedestrian street pattern, and is also the main entertainment and leisure gathering place for high educated and high income people. 2. Hefei Wanda Square marketing model for ladder pricing. That is, according to the factors such as consumer population and geographical location, according to the needs of different groups of different shops or housing to set different prices, to meet the customer status sense of belonging. 3. Wanda Square comprehensive sales model mainly depends on the brand advantages, whether its commercial square or bar street rely on the brand integration to develop, and continue to expand in the future rapid economic development.

\section{REFERENCES}

[1] Zeng Ming. Study on external risk of Wanda Real Estate Enterprise [D]. Shandong University.2016. (In Chinese)

[2] Deweych, Wei Jiang. Entrepreneurial mind, Strategic Entrepreneurship and Business Evolution [J]. Scientific research. 2015. (In Chinese)

[3] Yang Zhiguo. A study on the Design of large closed Shopping Center with dynamic Line [D]. Chongqing University.2015. (In Chinese)

[4] Gong Huiyan. Study on the Operation Mode and Development Strategy of Wanda City complex in Harbin [D]. Harbin University of Technology. 2015. (In Chinese)

[5] Wang Qiao. Study on disaster Prevention Planning of Urban Center area in High density Environment [D]. 2013. (In Chinese)

[6] Li Hailong. Study on Planning and Design Strategy of Wanda Commercial complex [D]. Beijing Construction University.2013. (In Chinese)

[7] Peter Hines, Riccardo Silvi, Monica Bartolini. Demand chain management: an integrative approach in automotive retailing [J]. Journal of Operations Management, 2002, 20 (6). 